\title{
Many Objective Optimization of a Magnetic Micro-Electro-Mechanical (MEMS) Micromirror with Bounded MP-NSGA Algorithm
}

\author{
Paolo Di Barba ${ }^{1}$ (D), Maria Evelina Mognaschi ${ }^{1}$ (D) and Elisabetta Sieni ${ }^{2, *(D)}$ \\ 1 Department of Electrical, Computer and Biomedical Engineering, University of Pavia, Via Ferrata 5, \\ 27100 Pavia, Italy; paolo.dibarba@unipv.it (P.D.B.); eve.mognaschi@unipv.it (M.E.M.) \\ 2 Department of Theoretical and Applied Sciences-DiSTA, University of Insubria, via J.H. Dunant, 3, \\ 21100 Varese, Italy \\ * Correspondence: elisabetta.sieni@uninsubria.it
}

Received: 31 July 2020; Accepted: 2 September 2020; Published: 4 September 2020

\begin{abstract}
The paper proposes the automated optimal design of a class of micro-electro-mechanical (MEMS) devices, based on a procedure of finite element analysis coupled to evolutionary optimization algorithms. A magnetic MEMS, used as an optical switch, is considered as the case study. In particular, the geometry of the device is optimized in order to maximize the actuation torque and minimize the power losses and the device volume. The optimization algorithms belong to the genetic class and, in particular, Migrated Parents - Non-Dominated Sorting Genetic Algorithm MP-NSGA, with three objective functions, is compared to NSGA-III.
\end{abstract}

Keywords: MEMS; micromirror; magnetic field; finite element analysis; many-objective optimization; Pareto Front

\section{Introduction}

It can be stated that the miniaturization of electromechanical systems is impacting contemporary society as deeply the mass production of electronic systems in recent decades. In fact, the impressive evolution of embedded system technologies has been fostered by the availability of miniaturized devices, which can behave like sensors or actuators: in a sense, these devices are the link between a physical process and the electric circuit processing the analogue signal (sensors) or governing the movement of a mechanical component (actuator) [1]. In this respect, the interest in micro-electro-mechanical system (MEMS) devices has substantially grown after the technological birth of MEMS, dating back to 1964 with the production of the first batch device [2]. However, only recently have the analysis and design of MEMS been approached in a methodologically mature way, based on the precise formulation of forward and inverse problems, which, in turn, might give rise to non-trivial mathematical problems to solve in at least an approximate way.

In the area of MEMS, two main lines of research can be observed. The former one, theoretically oriented, is devoted to the analysis and synthesis of multi-physics models [3-5] of, e.g., coupled thermal-elastic systems [3,6,7], electrostatic-elastic systems [3,8,9], magnetically actuated systems, and microfluidic systems [3,10-14]. In contrast, the latter is more focused on various application areas, for instance, the design and manufacturing of MEMS for biomedical systems with an emphasis on miniaturized bio-sensors and microdevices for tissue engineering $[9,15]$.

Several research projects are characterized by advanced theoretical models which aim at obtaining classes of closed-form solutions [16,17]. Alternatively, problem formulations which prove a priori conditions for the existence, uniqueness, and regularity of the solutions without explicitly computing them, have been developed $[18,19]$. When an explicit solution is not obtainable, methods finding 
approximate solutions by means of numerical techniques have been proposed: in particular, if the conditions of existence, uniqueness, and regularity are fulfilled, then the absence of ghost solutions is ensured [6,20-22].

Moreover, techniques for modeling magneto-thermo-elastic devices, considering the wave propagation in micro-domains with fixed or free boundaries, have been studied [23-26]. Obtaining the conditions of existence and uniqueness of solutions to inverse problems with moving boundaries is the core of several contributions [18,27-30]. Due to their simple construction technology, membrane MEMS devices are another class of devices often considered in many engineering applications [5,25,31-33].

There are many techniques of exciting a MEMS actuator; the ones which are commonly used can be classified into three categories, according to their relevant physical principle:

(i) The electrostatic excitation, based on an electric field which causes the controlled displacement of a movable component or the deformation of an elastic membrane;

(ii) The thermal excitation, which exploits the difference between the thermal expansion coefficients featuring two elastic materials when subject to a temperature gradient;

(iii) The magnetic excitation, based on the Lorentz force acting on a loop of current placed in an external magnetic field.

Specifically, magnetic actuation exhibits many advantages. In fact, it has a good linearity of movement versus excitation signal for a broad interval of values of current, low voltages needed for power supply, and hence low power consumption, and finally it is simple to control by means of a sequence of pulses of current $[11,34,35]$. For these reasons, in the paper, the field model of a magnetic MEMS used as a micromirror is considered, and a numerical method for the optimal shape design trading off multiple design criteria is proposed. The method is a very general one because it is based on the combination of a Finite Element model and a general purpose optimization algorithm. Hence, it is suitable for a broad class of MEMS devices, provided the designer sets up a parametric model of the device and defines the design variables, the objective functions and the constraints.

The manuscript is organized as follows: in Section 2, the principle of operation of the device is described; then, direct and inverse problems are formulated, specifically, the former is solved by means of a 3D finite-element model, while the solution of the latter is based on an algorithm of evolutionary computing inspired by Pareto-like optimality. Eventually, in Section 3, the results are presented and discussed.

\section{Materials and Methods}

\subsection{The Magnetic Micromirror}

A micromagnetic device used as an optical switch [36] is considered. It is based on the actuation of a ferromagnetic plate under the influence of a magnetic field variation. It consists of an $\mathrm{NdFeB}$ magnet (neodymium, iron, and boron alloy, Label A in Figure 1), two copper conductors carrying like currents (Label B in Figure 1), and a ferromagnetic plate (Label C in Figure 1) free to rotate around its axis in the point marked with $R$. The cross-section of the micromirror is shown in Figure 1. 


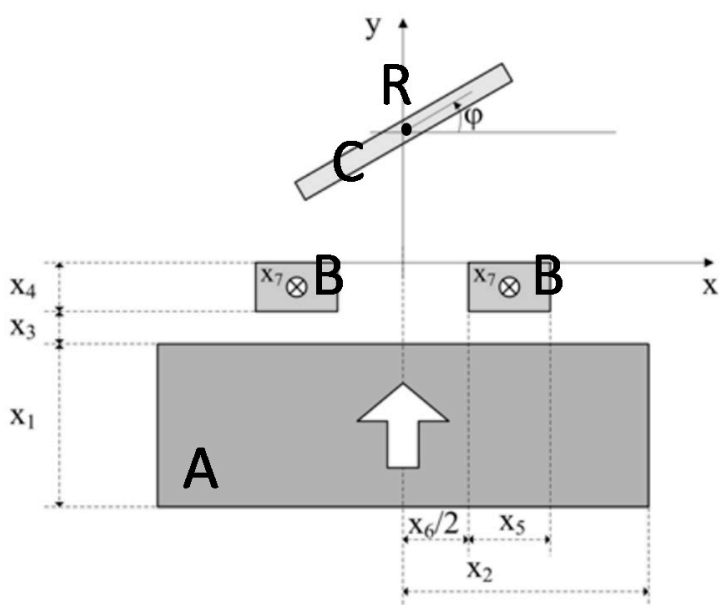

Figure 1. Geometry of the micromirror.

The residual induction of magnet is $1.2 \mathrm{~T}$ and the relative magnetic permeability is equal to 1.05. The plate is made of ferromagnetic material which is assumed to be linear with a relative permeability equal to $10^{3}$.

Typical dimensions of the device, hereinafter called the prototype, are: $x_{1}=100 \mu \mathrm{m}, x_{2}=1.2 \mathrm{~mm}$, $x_{3}=50 \mu \mathrm{m}, x_{4}=50 \mu \mathrm{m}, x_{5}=200 \mu \mathrm{m}, x_{6}=600 \mu \mathrm{m}, x_{7}=10 \mathrm{~A}$, plate length $=1 \mathrm{~mm}$, and plate height $=25 \mu \mathrm{m}[37,38]$. The magnet exhibits a square shaped base, hence the magnet depth in the third dimension, referring to Figure 1 , is equal to $2 \times x_{2}$. The plate depth is equal to its length $(1 \mathrm{~mm})$ and the two conductors are as long as the magnet in the third dimension, i.e., equal to $2 \times x_{2}$.

The torque holding the plate at the prescribed angle, evaluated at the point $R$, is due to the magnetic field of the permanent magnet in the absence of current, while the actuation torque, evaluated in point $R$, necessary to switch the plate angle is due to the magnetic field variation caused by a current pulse in the conductors. In particular, the actuation torque is calculated as the difference between the total torque (with currents on) and the holding torque (with currents off).

\subsection{Field Analysis}

Given the geometry in Figure 1, the field analysis problem consists of finding the magnetic field distribution for a given plate angle and a given amplitude $I$ of the current pulse. Since it is assumed to neglect the transient behavior, a steady-state analysis is considered. Hence, the problem to be solved, in terms of magnetic vector potential $\bar{A}$, is

$$
\nabla^{2} \bar{A}=-\mu \bar{J}-\nabla \times \bar{B}_{0}
$$

subject to suitable boundary conditions, where $\bar{J}$ is the specific current, which is supposed to be supplied to the coil by an external source of DC current I. Moreover, $\mu$ is the magnetic permeability and $\bar{B}_{0}$ is the magnetic remanence of the permanent magnet. The magnetic induction field $\bar{B}$ is then calculated as

$$
\bar{B}=\nabla \times \bar{A}
$$

The torque acting on the plate is calculated by means of the Maxwell's stress tensor [9]: the force $F$ acting on each point $Q$ of a closed surface surrounding the plate is calculated as

$$
\bar{F}=\int_{\Omega} \nabla \cdot T d \Omega=\int_{\Gamma} T \cdot \bar{n} d \Gamma
$$

where $\bar{n}$ is the outward normal unit vector and Tis the Maxwell's magnetic stress tensor. 
Since the tensor is symmetric, the torque corresponding to (3) is given by

$$
\bar{M}=\int_{\Gamma} \bar{r}_{Q R} \times T \cdot \bar{n} d \Gamma
$$

where $\bar{r}_{Q R}$ is the position vector of a given point $Q$ on $\Gamma$ with respect to the rotation axis in $R$, which is the center point of the plate.

Based on (4), the holding torque and actuation torque were independently defined and computed. In particular, the holding torque is defined as

$$
\bar{M}_{h}=\int_{\Gamma} \bar{r}_{Q R} \times T_{I=0} \cdot \bar{n} d \Gamma
$$

i.e., the no-load torque due to magnet only, while the total torque is defined as

$$
\bar{M}_{t}=\int_{\Gamma} \bar{r}_{Q R} \times T_{I \neq 0} \cdot \bar{n} d \Gamma
$$

i.e., the on-load torque, due to both magnet and current.

The actuation torque is eventually computed as $\bar{M}_{a}=\bar{M}_{t}-\bar{M}_{h}$.

In order to solve the field analysis problem (1)-(4) given the geometry of magnet and conductors (i.e., the forward problem), a 3D Finite Element FE model (Figure 2) was built with MagNet by Mentor Infolytica [39]; the field simulation was obtained by means of the magnetostatic solver.

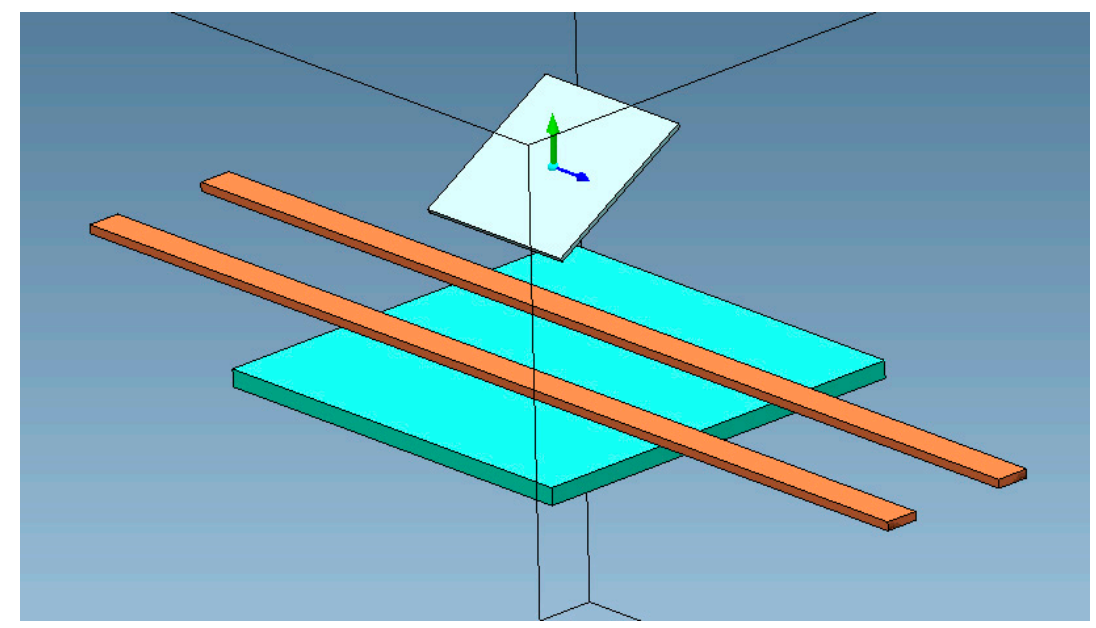

Figure 2. 3D geometry of the FE model.

In the real device, the length of the copper wires is equal to the magnet depth. For modelling purposes, however, the copper conductors must start from and end at a face of the airbox; this feature is required by the FE code used, in order to have a geometrically consistent model. This is why in the model, (see Figures 2 and 3) the copper conductors are longer than the magnet.

A typical finite-element mesh, shown in Figure 3, is composed of about 350,000 tetrahedral elements; second-order polynomial Lagrangian elements are considered. The torque-angle curve has been computed based on the Maxwell's stress tensor, for both holding and actuation torque. The torques calculated for the prototype are shown in Figure 4. 


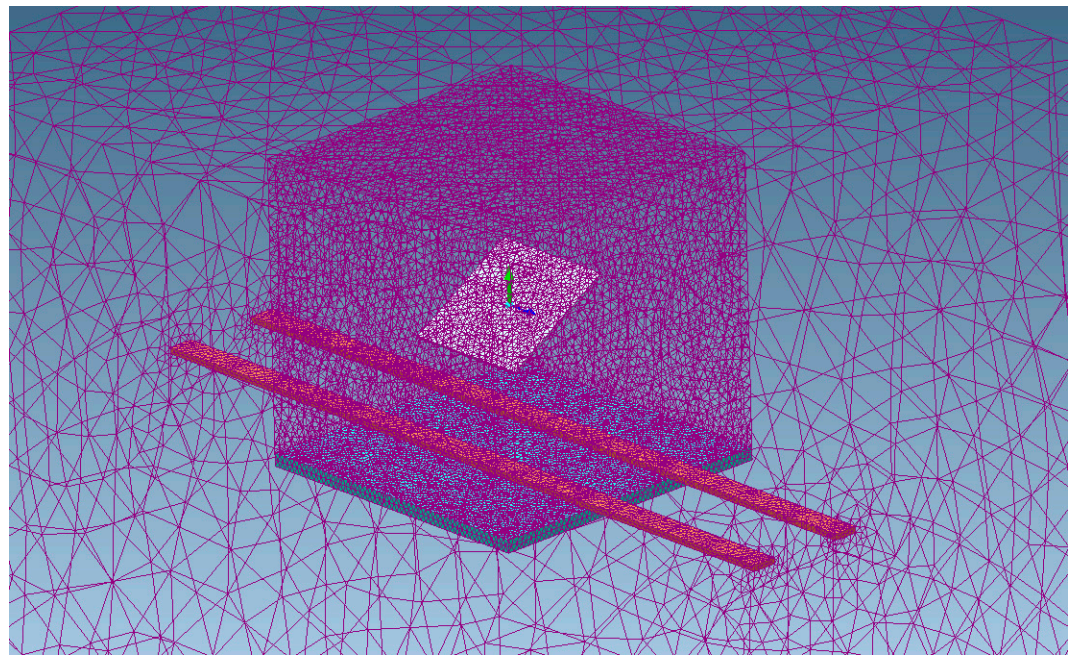

Figure 3. Mesh of the FE model.

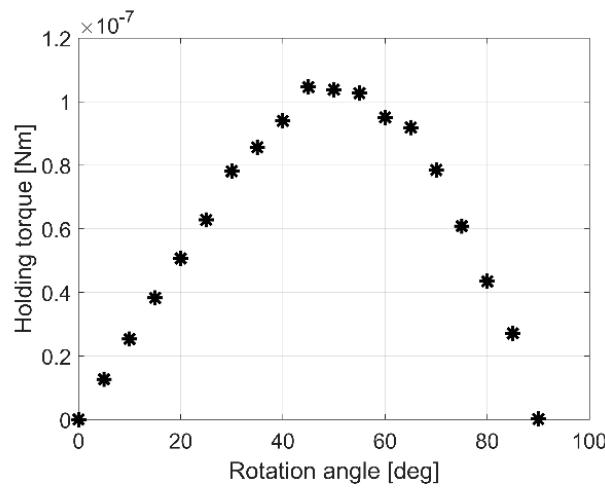

(a)

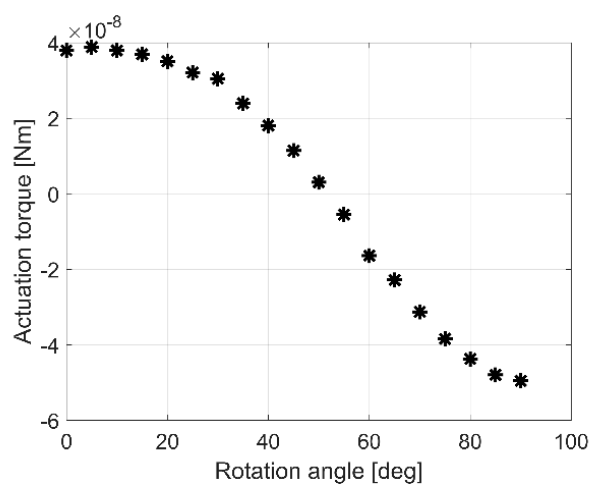

(b)

Figure 4. (a) Holding and (b) actuation torque calculated for the prototype.

The actuation torque of the prototype was computed for different current values, considering the rotation angle equal to 10 degrees. The torque versus current curve is shown in Figure 5.

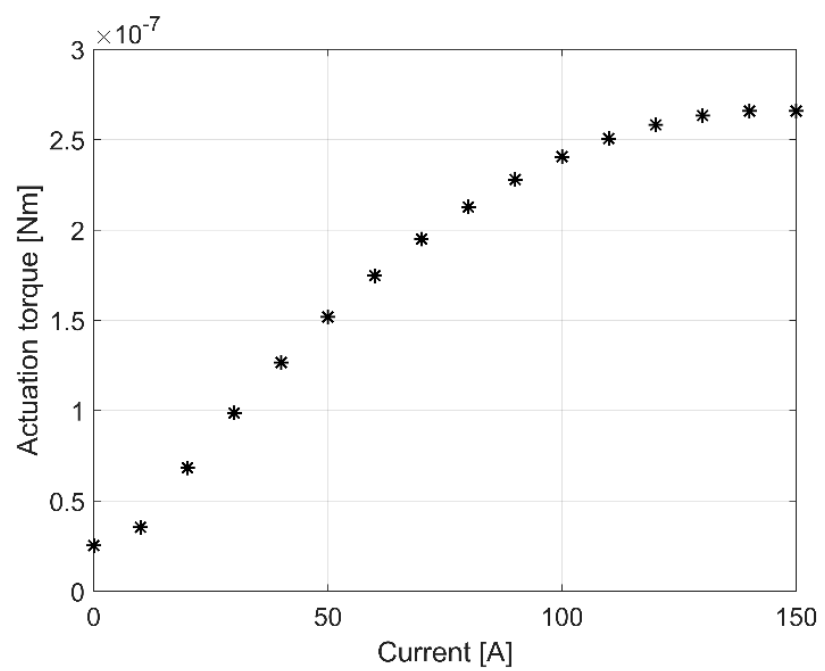

Figure 5. Actuation torque versus current, referred to the prototype for a rotation angle $\varphi=10^{\circ}$. 
It can be noted that the actuation torque versus current curve is rather linear for currents up to $100 \mathrm{~A}$. In fact, the linear behavior of the actuation torque is one of the advantages of magnetic MEMS.

The values of the torques calculated with the 3D model are in accordance with those calculated in previous papers by the authors $[37,38]$ with the $2 \mathrm{D}$ model. For the sake of comparison, let it be considered that the depth of the 2D model is $10 \mu \mathrm{m}$, while the plate in the 3D model is 1-mm long in the third dimension: for a rotation angle $\varphi=10^{\circ}$ the holding torque is equal to $2.53 \times 10^{-8} \mathrm{Nm}$ for the 3D model, while it is equal to about $4.39 \times 10^{-11} \mathrm{Nm}$ for the $2 \mathrm{D}$ model. Therefore, for the 2D model, the holding torque is $0.44 \times 10^{-8} \mathrm{Nm}$ per mm of depth. The torque resulting from the 3D model $\left(2.53 \times 10^{-8} \mathrm{Nm}\right)$ is comparable with the torque of the $2 \mathrm{D}$ model $\left(0.44 \times 10^{-8} \mathrm{Nm}\right)$. Although a full comparison between the two models is hardly possible, because of the different depth of the various components, the two torque values are in reasonable agreement.

\subsection{Optimization Problem}

The design (or inverse) problem-i.e., find the shape of the MEMS device fulfilling the prescribed performance-is based on three design criteria which, in turn, depend on a set of seven degrees of freedom, here called design variables. The latter control the geometry of permanent magnet and current-carrying conductors, and are subject to a set of constraints. Design criteria are modelled via objective functions dependent on the design variables: this way, the inverse problem can be converted into a constrained optimization problem, subsequently solved by means of an algorithm of evolutionary computing (see Section 2.4).

In particular, the seven-dimensional vector of design variable vector is $X=\left[x_{1}, x_{2}, x_{3}, x_{4}, x_{5}, x_{6}\right.$, $x_{7}$ ] where $x_{1}, \ldots, x_{6}$ are geometrical quantities (see Figure 1 ), while $x_{7}$ is the value of current carried by each conductor.

Moreover, the following objective functions are defined for a prescribed mirror position $\varphi=10^{\circ}$ : ohmic power loss in conductors, to be minimized

$$
f_{1}(X)=2 x_{2} x_{7}^{2}\left(\sigma x_{4} x_{5}\right)^{-1}
$$

with the copper conductivity $\sigma=5.77 \times 10^{7} \mathrm{Sm}^{-1}$;

Actuation torque acting on the mirror, to be maximized

$$
f_{2}(X)=\int_{\Gamma} \bar{r}_{Q R} \times T(X)_{I \neq 0} \cdot \bar{n} d \Gamma-\int_{\Gamma} \bar{r}_{Q R} \times T(X)_{I=0} \cdot \bar{n} d \Gamma
$$

excitation system (i.e., conductors and magnet) volume, to be minimized

$$
f_{3}(X)=\left(2 x_{2}\right)^{2}\left(x_{1}+x_{3}+x_{4}\right)
$$

All in one, meeting the design criteria would help in the design of an efficient and miniaturized device with a good torque performance. From the modelling viewpoint, it can be noted that the computation of $f_{1}$ and $f_{3}$ is inexpensive (closed-form Equations (7) and (9)), while $f_{2}$ is computationally demanding because it is a field-dependent objective (finite-element simulations).

Eventually, three behavioral constraints are prescribed, namely, lower thresholds for holding and actuation torque are set to $10^{-8}$ and $10^{-9} \mathrm{Nm}$, respectively; moreover, the pulsed current density value in the conductors is constrained to be lower than $5 \times 10^{9} \mathrm{Am}^{-1}$. In Table 1 , the range of variation in the design variables and the three constraints are shown.

The optimal design problem can be formally cast as follows: starting from an initial guess, identify the family of geometries such that $f_{1}(X)$ is minimized, $f_{2}(X)$ is maximized and $f_{3}(X)$ is minimized, subject to the inequality constraints (Table 1) and to field Equations (1)-(6). The simultaneous optimization of objective vector $\left(f_{1}, f_{2}, f_{3}\right)$ is intended in the Pareto sense; therefore, the family of optimal solutions called non-dominated solutions is the unknown [40]. Traditionally, methods and algorithms for solving 
bi-objective problems has been developed, while approaches to higher-order objective spaces have been considered more recently [40]. In fact, a tri-objective problem is proposed here.

Table 1. Variation ranges of the design variables and constraints.

\begin{tabular}{ccccc}
\hline Design Variable & Minimum & Maximum & Constraint & Threshold \\
\hline $\mathrm{x}_{1}$ & $50 \mu \mathrm{m}$ & $150 \mu \mathrm{m}$ & Holding torque & $>10^{-8} \mathrm{Nm}$ \\
$\mathrm{x}_{2}$ & $1 \mathrm{~mm}$ & $2 \mathrm{~mm}$ & & \\
$\mathrm{x}_{3}$ & $25 \mu \mathrm{m}$ & $75 \mu \mathrm{m}$ & Actuation torque & $>10^{-9} \mathrm{Nm}$ \\
$\mathrm{x}_{4}$ & $25 \mu \mathrm{m}$ & $75 \mu \mathrm{m}$ & & \\
$\mathrm{x}_{5}$ & $100 \mu \mathrm{m}$ & $300 \mu \mathrm{m}$ & Current density & $<5 \times 10^{9} \mathrm{Am}^{-2}$ \\
$\mathrm{x}_{6}$ & $300 \mu \mathrm{m}$ & $900 \mu \mathrm{m}$ & & \\
$\mathrm{x}_{7}$ & $0 \mathrm{~A}$ & $150 \mathrm{~A}$ & & \\
\hline
\end{tabular}

\subsection{Optimization Algorithms}

As far as the selection of optimization algorithms to solve problem (7)-(9) is concerned, the following remarks can be put forward. The arguments minimizing (7) could be found analytically; the same holds for (9), while the argument maximizing (8) could be numerically approximated by resorting to a zero-order deterministic algorithm, e.g., the Nelder-Mead simplex algorithm or the Powell algorithm of conjugate directions linked to the finite-element solver; this way, the three independent solutions (i.e., two minimizers and one maximizer) would be found. In multi-objective optimization, however, the identification of the Pareto front trading off conflicting objectives is the aim: it cannot be achieved except through resorting to a strategy of evolutionary computing, because deterministic computing does not make it possible the non-dominated sorting of a set of solutions [41], and the tri-objective problem here considered is no exception.

In particular, the selected optimization algorithms belong to the class of genetic Algorithms and they are based on the classical Non-Dominated Sorting Genetic Algorithm, (NSGA-II) [41-46]. In particular, Migration - Non-Dominated Sorting Genetic Algorithm M-NSGA includes the Migration concept introduced in [47-49] with a self-adaptation mechanism that allows for the modulation of the size of the migrated population in [50-52]. In [47], the migrated population is introduced after the generation step and the new genetic heritage due to the migrated individuals will be active in the next generation if the individuals survive after selection. In this paper, an alternative version of the M-NSGA algorithm, named MP-NSGA, is used [53].

In the Non-Dominated-Sorting Genetic Algorithm strategy, the initial population is composed of a random set of $\mathrm{N}$ individuals. The new generation is obtained by applying the genetic operator to the parent population of the previous step: in general, for a pair of individuals, one or two offspring are generated by means of cross-over genetic rules [43]; in the NSGA-II strategy, the new generation is the result of the selection of the individuals that best fit with a selection criteria, i.e., the one that minimizes the objective functions.

In the NSGA-II algorithm at each generation, a population of $\mathrm{N}$ parents generates up to $\mathrm{N}$ sons (up to $2 \mathrm{~N}$ individuals after generation step) that, after a selection step, produce a new population of $\mathrm{N}$ individuals [43]. In the M-NSGA algorithm, a new population [47,50,51], with a size variable in number of individuals from 5 to $\mathrm{N}$, immigrates after the generation step, so improved individuals could modify the genetic heritage of the original population if they survive after selection. The flow chart is shown in Figure 6a. In the MP-NSGA algorithm, immigration occurs before generation step, so the genetic heritage of the migrated population can affect the successive generation step of the new individuals. Moreover, in this case, the size of the immigrated population is smaller, and the number of individuals is variable between 5 to N/2: then, the generation can generate up to $3 \mathrm{~N} / 2 \mathrm{new}$ individuals. The proposed version of the M-NSGA algorithm includes the check of three problem boundaries. In case a solution does not satisfy even one of the constraints, all the objective functions are set to $10^{10}$. This way, these individuals are discarded during the selection step. The flow chart of 
the bounded version of the MP-NSGA algorithm is shown in Figure $6 \mathrm{~b}$. The algorithm stops after a given number of generations.

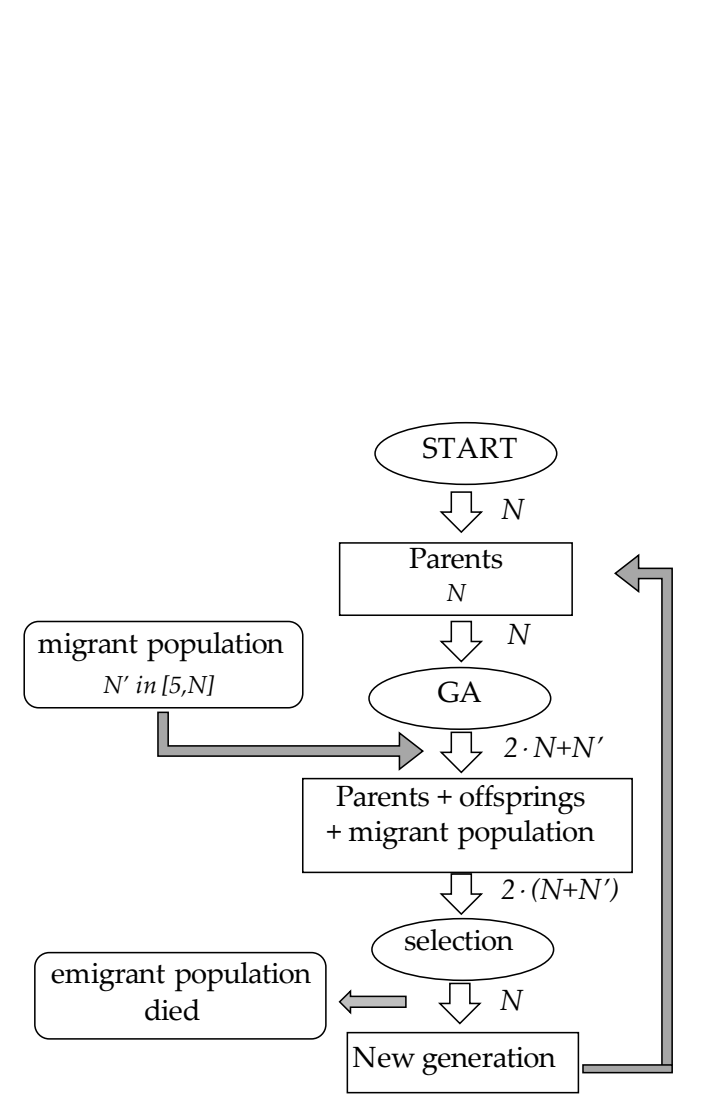

(a)

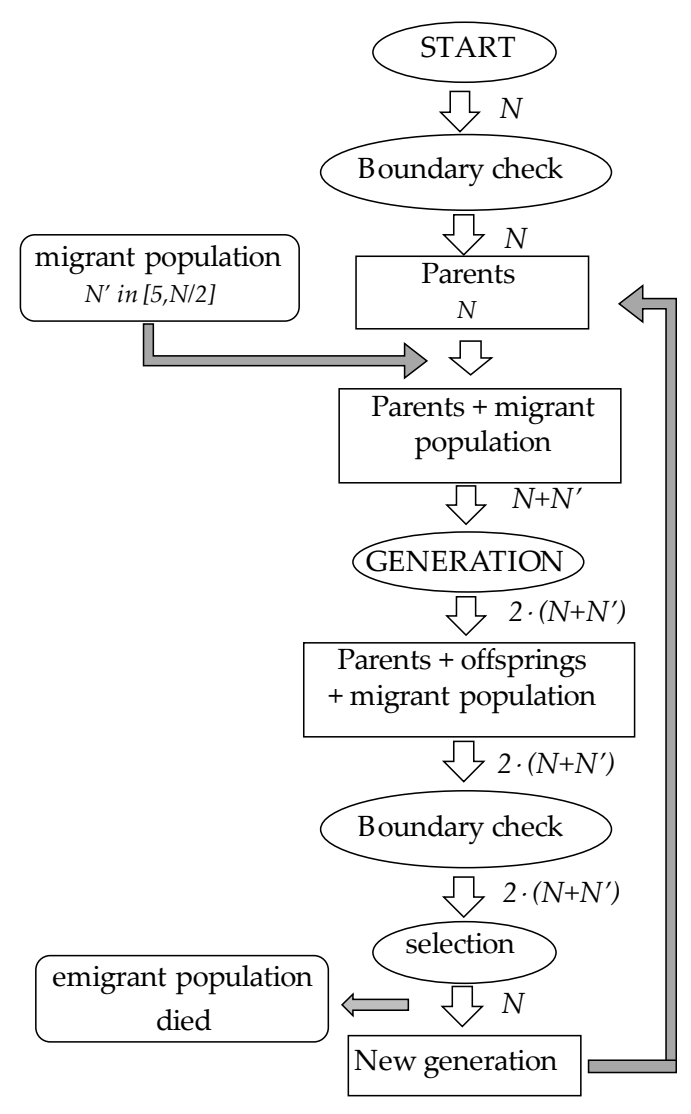

(b)

Figure 6. Optimization flow chart (a) M-NSGA and (b) MP-NSGA with boundary check.

NSGA-III is able to manage up to 15 objective functions and is based on NSGA-II for the individual generation and classification of Non-Dominated Sorting levels [53]. The algorithm uses reference points to preserve diversity. The initial population is formed by $\mathrm{N}$ individuals, with being $\mathrm{N}$ a multiple of four larger than $\mathrm{H}$, which is the number of reference points chosen randomly in the design variable space [54]. After each generation step, the operators' non-domination sorting and selection of the reference points are applied to preserve diversity in the population. First, the current minimum of each objective function is searched for and the scaling factors for each objective function are set to the current maximum value for each objective function. Maximum values generate a hyperplane where the reference points are mapped. Each generated individual is assigned to the closer reference point mapped in the hyper-plane following the procedure in [53] related to niche-preservation. In practice, if more points are associated with one reference point, only one is chosen to belong to the new $P_{t+1}$ population. This process is repeated until $\mathrm{N}$ individuals are selected.

\section{Results}

The optimization problem is solved running MP-NSGA with 20 individuals for 50 generations and NSGA-III with the same number of individuals and generations. The objective space is three-dimensional, however, a 3D plot of the results does not allow a good evaluation of the results. Hence, for the sake of clarity, $2 D$ orthogonal projections of the objective space into $f_{1}-f_{2}, f_{1}-f_{3}$ and $f_{2}-f_{3}$ planes, respectively, are done. They are shown in Figures 7-9. 




Figure 7. $\mathrm{f}_{1}-\mathrm{f}_{2}$ projection of the objective space: dot-individuals, cross-NSGA-III solutions, circle-MP-NSGA solutions.

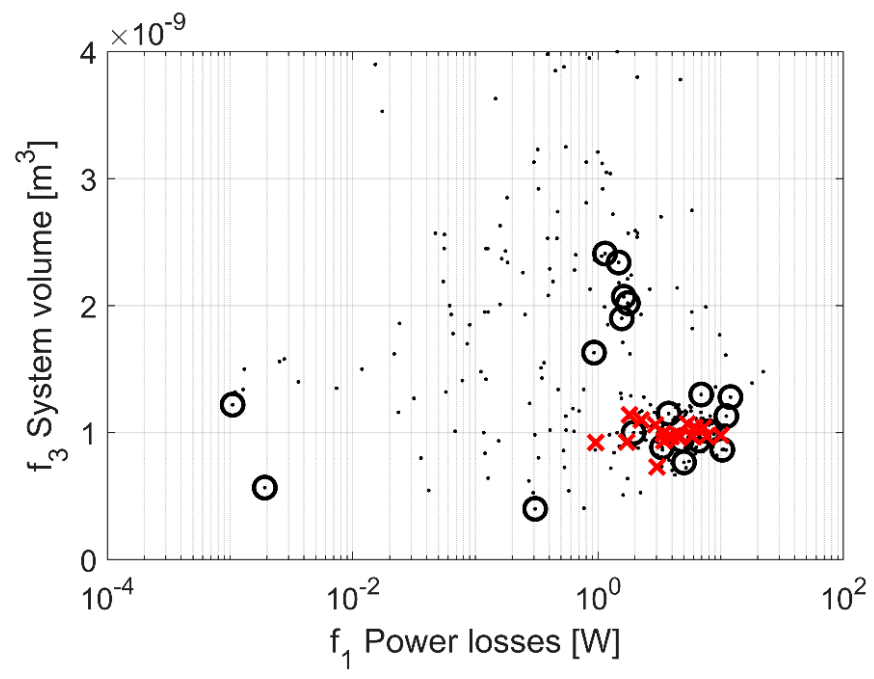

Figure 8. $f_{1}-f_{3}$ projection of the objective space: dot-individuals, cross-NSGA-III solutions, circle-MP-NSGA solutions.

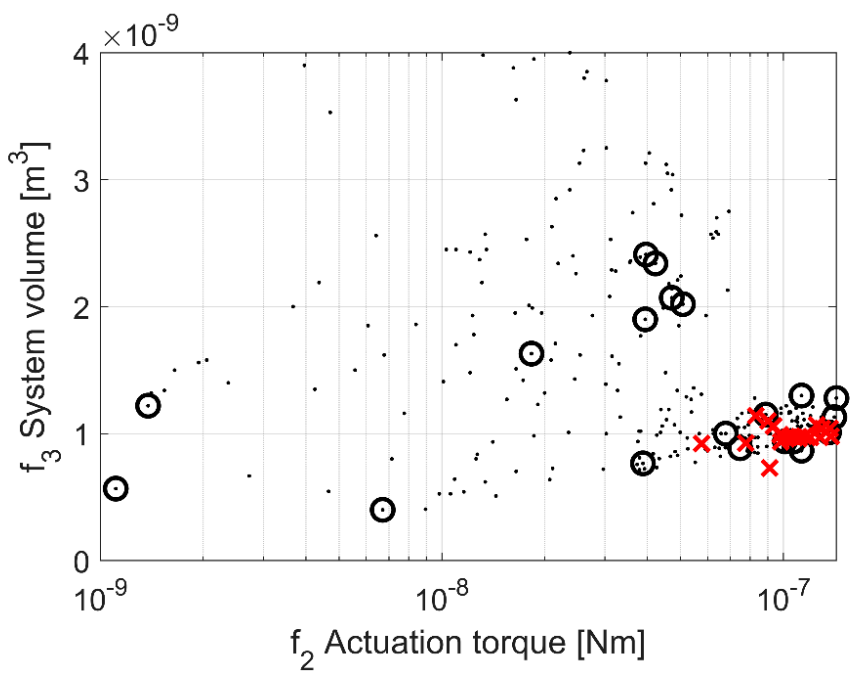

Figure 9. $f_{2}-f_{3}$ projection of the objective space: dot-individuals, cross-NSGA-III solutions, circle-MP-NSGA solutions. 
From Figures 7-9, it can be noted that MP-NSGA is able to better explore the search space than NSGA-III. This is a typical benefit of the migration operator introduced in MP-NSGA.

On the other hand, however, NSGA-III appears to better approximate the Pareto front, because there are solutions obtained by MP-NSGA, which are dominated by NSGA-III solutions.

In Table 2, the solutions obtained with the two methods are shown.

Table 2. Solutions obtained with MP-NSGA and NSGA-III.

\begin{tabular}{cccccc}
\hline & MP-NSGA & & \multicolumn{3}{c}{ NSGA-III } \\
\hline $\mathbf{f}_{\mathbf{1}}$ & $\mathbf{f}_{\mathbf{2}}$ & $\mathbf{f}_{\mathbf{3}}$ & $\mathbf{f}_{\mathbf{1}}$ & $\mathbf{f}_{\mathbf{2}}$ & $\mathbf{f}_{\mathbf{3}}$ \\
\hline $1.91 \times 10^{-3}$ & $1.11 \times 10^{-9}$ & $5.67 \times 10^{-10}$ & 10 & $1.38 \times 10^{-7}$ & $9.8 \times 10^{-10}$ \\
0.31 & $6.71 \times 10^{-9}$ & $4.00 \times 10^{-10}$ & 1.8 & $8.31 \times 10^{-8}$ & $1.14 \times 10^{-9}$ \\
$1.05 \times 10^{-3}$ & $1.38 \times 10^{-9}$ & $1.22 \times 10^{-9}$ & 3.39 & $9.79 \times 10^{-8}$ & $9.92 \times 10^{-10}$ \\
12.0 & $1.43 \times 10^{-7}$ & $1.28 \times 10^{-9}$ & 7.68 & $1.28 \times 10^{-7}$ & $9.71 \times 10^{-10}$ \\
1.14 & $3.96 \times 10^{-8}$ & $2.41 \times 10^{-9}$ & 7.27 & $1.37 \times 10^{-7}$ & $1.04 \times 10^{-9}$ \\
7.96 & $1.36 \times 10^{-7}$ & $1.01 \times 10^{-9}$ & 1.72 & $7.76 \times 10^{-8}$ & $9.25 \times 10^{-10}$ \\
3.76 & $8.88 \times 10^{-8}$ & $1.15 \times 10^{-9}$ & 3.44 & $9.82 \times 10^{-8}$ & $9.37 \times 10^{-10}$ \\
10.3 & $1.13 \times 10^{-7}$ & $8.66 \times 10^{-10}$ & 4.59 & $1.11 \times 10^{-7}$ & $9.61 \times 10^{-10}$ \\
6.93 & $1.13 \times 10^{-7}$ & $1.30 \times 10^{-9}$ & 5.91 & $1.2 \times 10^{-7}$ & $9.71 \times 10^{-10}$ \\
5.01 & $3.88 \times 10^{-8}$ & $7.66 \times 10^{-10}$ & 6.14 & $1.3 \times 10^{-7}$ & $1.04 \times 10^{-9}$ \\
11.1 & $1.41 \times 10^{-7}$ & $1.13 \times 10^{-9}$ & 2.94 & $9.36 \times 10^{-8}$ & $1.06 \times 10^{-9}$ \\
1.75 & $5.08 \times 10^{-8}$ & $2.02 \times 10^{-9}$ & 4.59 & $1.11 \times 10^{-7}$ & $9.74 \times 10^{-10}$ \\
4.81 & $1.01 \times 10^{-7}$ & $9.39 \times 10^{-10}$ & 5.35 & $1.25 \times 10^{-7}$ & $1.07 \times 10^{-9}$ \\
1.62 & $4.71 \times 10^{-8}$ & $2.07 \times 10^{-9}$ & 3.03 & $9.11 \times 10^{-8}$ & $7.29 \times 10^{-10}$ \\
6.64 & $1.07 \times 10^{-7}$ & $9.38 \times 10^{-10}$ & 4.59 & $1.15 \times 10^{-7}$ & $9.80 \times 10^{-10}$ \\
0.97 & $1.83 \times 10^{-8}$ & $1.63 \times 10^{-9}$ & 5.90 & $1.20 \times 10^{-7}$ & $9.71 \times 10^{-10}$ \\
1.95 & $6.78 \times 10^{-8}$ & $1.00 \times 10^{-9}$ & 2.26 & $9.02 \times 10^{-8}$ & $1.10 \times 10^{-9}$ \\
1.47 & $4.22 \times 10^{-8}$ & $2.34 \times 10^{-9}$ & 3.76 & $1.04 \times 10^{-7}$ & $9.71 \times 10^{-10}$ \\
1.56 & $3.94 \times 10^{-8}$ & $1.90 \times 10^{-9}$ & 0.96 & $5.76 \times 10^{-8}$ & $9.22 \times 10^{-10}$ \\
3.32 & $7.47 \times 10^{-8}$ & $8.85 \times 10^{-10}$ & 3.95 & $1.08 \times 10^{-7}$ & $9.69 \times 10^{-10}$ \\
\hline
\end{tabular}

In the following, an in-depth analysis of the solutions obtained with MP-NSGA is made. In Figures 10-12, the starting and final solutions are shown; moreover, the prototype and other reference solutions are highlighted in each picture.

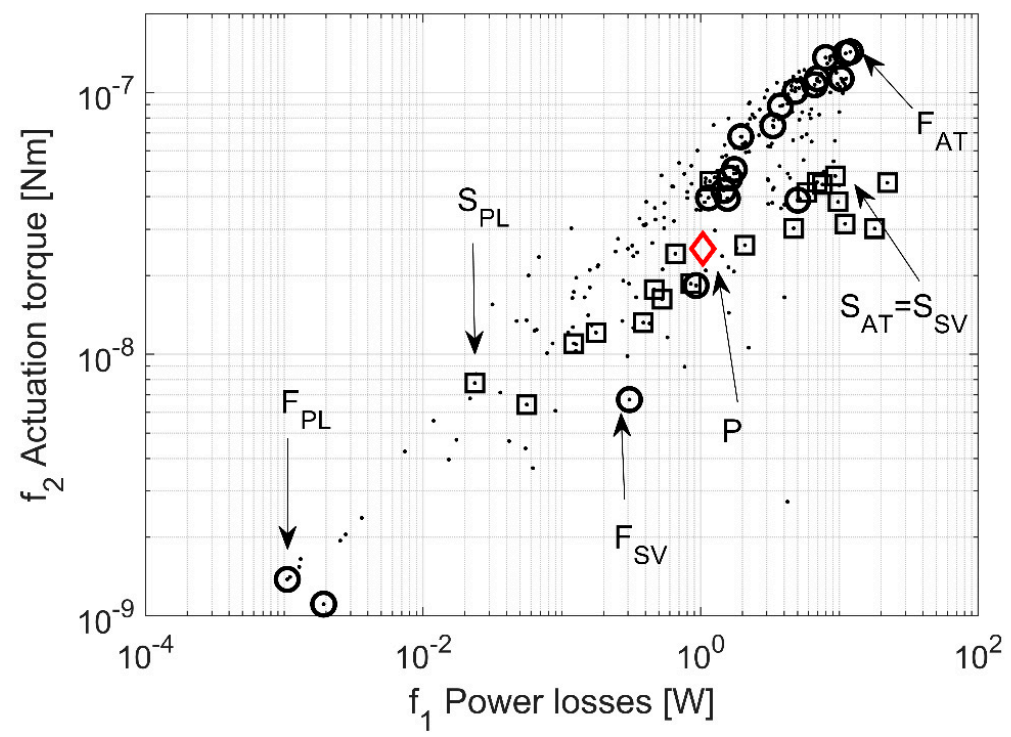

Figure 10. $f_{1}-f_{2}$ projection of the objective space: dot-individuals, square-starting points, circle-final solutions. 


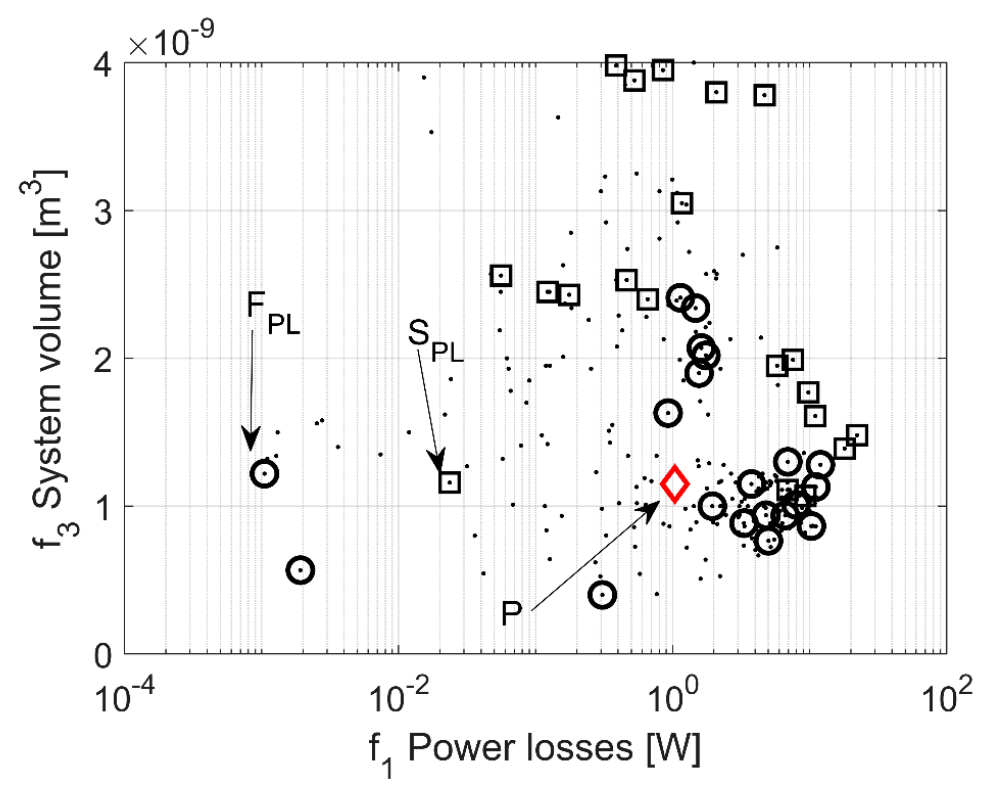

Figure 11. $\mathrm{f}_{1}-\mathrm{f}_{3}$ projection of the objective space: dot-individuals, square-starting points, circle-final solutions.



Figure 12. $f_{2}-f_{3}$ projection of the objective space: dot-individuals, square—starting points, circle-final solutions.

The points $S_{P L}$ and $F_{P L}$ highlighted in Figures 9-11 are the solutions with the lowest power losses in the first generation and in the last one, respectively. In Table 3, the values of the design variables and the relevant objective function values are shown. For the sake of comparison, the prototype proposed in $[37,38]$ (P point in Figures 7-9) is also reported. 
Table 3. Values of the design variables and objective functions for points $\mathrm{P}, \mathrm{S}_{\mathrm{PL}}$ and $\mathrm{F}_{\mathrm{PL}}$ (Figures 9-11).

\begin{tabular}{cccccccc}
\hline $\begin{array}{c}\text { Design } \\
\text { Variable }\end{array}$ & $\mathbf{P}$ & $\mathbf{S}_{\mathbf{P L}}$ & $\mathbf{F}_{\mathbf{P L}}$ & Objective Function & $\mathbf{P}$ & $\mathbf{S}_{\mathbf{P L}}$ & $\mathbf{F}_{\mathbf{P L}}$ \\
\hline $\mathrm{x}_{1}[\mu \mathrm{m}]$ & 100 & 144 & 140 & $\mathrm{f}_{1}$ power losses $[\mathrm{W}]$ & 1.04 & $2.36 \times 10^{-2}$ & $1.05 \times 10^{-3}$ \\
$\mathrm{x}_{2}[\mathrm{~mm}]$ & 1.2 & 1.17 & 1.24 & & & & \\
$\mathrm{x}_{3}[\mu \mathrm{m}]$ & 50 & 33.8 & 28.9 & $\mathrm{f}_{2}$ actuation torque & $2.53 \times 10^{-8}$ & $7.76 \times 10^{-9}$ & $1.38 \times 10^{-9}$ \\
$\mathrm{x}_{4}[\mu \mathrm{m}]$ & 50 & 34.6 & 29.2 & {$[\mathrm{Nm}]$} & & & \\
$\mathrm{x}_{5}[\mu \mathrm{m}]$ & 200 & 178 & 175 & $\mathrm{f}_{3}$ system volume $\left[\mathrm{m}^{3}\right]$ & $1.15 \times 10^{-9}$ & $1.16 \times 10^{-9}$ & $1.22 \times 10^{-9}$ \\
$\mathrm{x}_{6}[\mu \mathrm{m}]$ & 600 & 532 & 485 & & & & \\
$\mathrm{x}_{7}$, current $[\mathrm{A}]$ & 10 & 1.89 & 0.35 & & & \\
\hline
\end{tabular}

While in Table 3 the solutions with the lowest power losses of the first and last generations are shown, in Table 4, the solutions with the highest actuation torque of the first and last iterations are shown, along with the solutions with the lowest system volume of the first and last iterations. However, the solution of the first iteration with the lowest system volume, $\mathrm{S}_{\mathrm{SV}}$, is, by chance, the same with the highest actuation torque, $\mathrm{S}_{\mathrm{AT}}$.

Table 4. Values of the design variables and objective functions of solutions with highest actuation torque $\left(\mathrm{S}_{\mathrm{AT}}\right.$ and $\left.\mathrm{F}_{\mathrm{AT}}\right)$ and lowest system volume $\left(\mathrm{S}_{\mathrm{SV}}\right.$ and $\left.\mathrm{F}_{\mathrm{SV}}\right)$.

\begin{tabular}{cccccccc}
\hline $\begin{array}{c}\text { Design } \\
\text { Variable }\end{array}$ & $\mathbf{S}_{\mathbf{A T}}=\mathbf{S}_{\mathbf{S V}}$ & $\mathbf{F}_{\mathbf{A T}}$ & $\mathbf{F}_{\mathbf{S V}}$ & Objective Function & $\mathbf{S}_{\mathbf{A T}}=\mathbf{S}_{\mathbf{S V}}$ & $\mathbf{F}_{\mathbf{A T}}$ & $\mathbf{F}_{\mathbf{S V}}$ \\
\hline $\mathrm{x}_{1}[\mu \mathrm{m}]$ & 134 & 150 & 50 & $\mathrm{f}_{1}$ power losses $[\mathrm{W}]$ & 9.34 & 12 & 0.31 \\
$\mathrm{x}_{2}[\mathrm{~mm}]$ & 1.02 & 1.18 & 1 & & & & \\
$\mathrm{x}_{3}[\mu \mathrm{m}]$ & 45.9 & 25 & 25 & $\mathrm{f}_{2}$ actuation torque & $4.8 \times 10^{-8}$ & $1.43 \times 10^{-7}$ & $6.71 \times 10^{-9}$ \\
$\mathrm{x}_{4}[\mu \mathrm{m}]$ & 75 & 55 & 25 & {$[\mathrm{Nm}]$} & & & \\
$\mathrm{x}_{5}[\mu \mathrm{m}]$ & 156 & 222 & 300 & $\mathrm{f}_{3}$ system volume $\left[\mathrm{m}^{3}\right]$ & $1.07 \times 10^{-9}$ & $1.28 \times 10^{-9}$ & $4 \times 10^{-10}$ \\
$\mathrm{x}_{6}[\mu \mathrm{m}]$ & 827 & 300 & 900 & & & & \\
$\mathrm{x}_{7}$, current $[\mathrm{A}]$ & 55.6 & 60.1 & 8.16 & & & & \\
\hline
\end{tabular}

The geometry of the three, up to twenty final solutions, $\mathrm{F}_{\mathrm{PL}}, \mathrm{F}_{\mathrm{AT}}$ and $\mathrm{F}_{\mathrm{SV}}$, is shown in Figure 13.

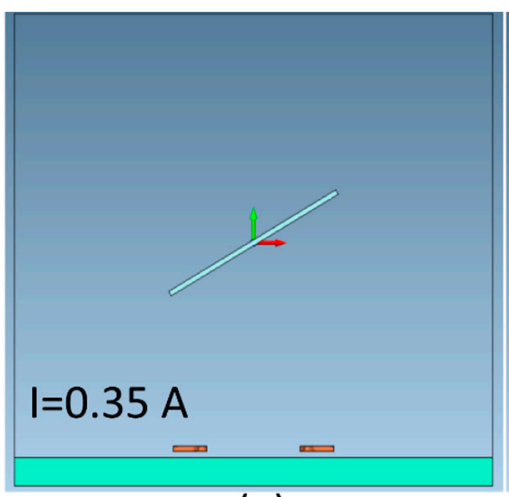

(a)



(b)

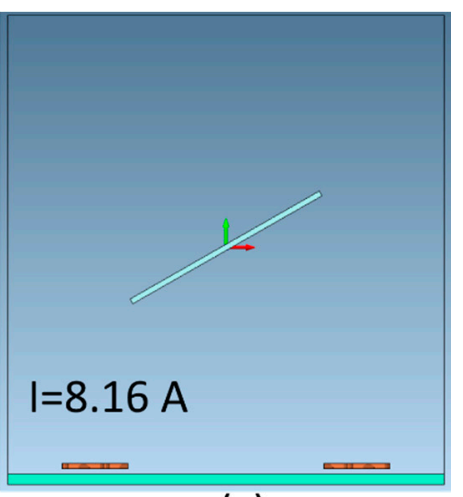

(c)

Figure 13. Geometry of solutions $\mathrm{F}_{\mathrm{PL}}(\mathbf{a}), \mathrm{F}_{\mathrm{AT}}(\mathbf{b}), \mathrm{F}_{\mathrm{SV}}(\mathbf{c})$.

\section{Discussion}

In the past, a bi-objective formulation [37] as well as a tri-objective formulation [38] of the optimization problem, was proposed and solved by the authors. The bi-objective formulation [34] reads: having prescribed lower thresholds for holding and actuation torque, given the plate angle $\varphi=10^{\circ}$, find the geometry of magnet and conductors, as well as the amplitude of the current pulse, so that the power loss in the conductors and the magnet volume are both minimized. Moreover, there were thresholds for the holding torque and for the actuation torque, set to 1 and $0.25 \mathrm{nNm}$, respectively. 
The tri-objective formulation [35] reads: having prescribed lower thresholds for holding torque $\left(10^{-8} \mathrm{Nm}\right)$ and actuation torque $\left(10^{-9} \mathrm{Nm}\right)$, given the mirror position $\varphi=10^{\circ}$, find the geometry of magnet and conductors, as well as the current pulse amplitude, such that power loss in conductors $\left(f_{1}\right)$, weighted material cost $\left(f_{2}\right)$, and excitation system volume (i.e., conductors and magnet, $\left.f_{3}\right)$ are simultaneously minimized in the Pareto sense.

However, both optimization problems were based on a 2D model of the micromirror, while, in this paper, a 3D model is considered. This improvement allows good accuracy in the solution of the direct problem. In fact, the geometry of the system is clearly a 3D one due to the different depths of the device components: only a 3D model is able to accurately simulate the field distribution in the model and, hence, relevant quantities, e.g., forces and torques. A comparison of the torque calculated by means of both models (2D and 3D) is made (see the end of Section 2.2); there is an agreement between the two models, but the 3D model is more reliable because the field distribution in the third dimension is taken into account.

Moreover, the tri-objective formulation was solved by means of P-EStra, a Paretian Evolution strategy of lowest order. For each optimization run, only one solution was found. In this paper, a migration-assisted algorithm (MP-NSGA), which runs with a population of $\mathrm{N}$ individuals at a time, is used; the Paretian solution found is then composed of $\mathrm{N}=20$ individuals.

Looking at the results, the following comments can be put forward. From Table 3, it can be noted that the solutions with the lowest power losses are characterized by relatively thick magnets (high values of magnet thickness $x_{1}$ ), and rather thin coils (low values of $x_{4}$ ) carrying a low current (low values of $x_{7}$ ). The length of the coils and the distance between them (design variables $x_{5}$ and $x_{6}$, respectively) have values in the middle of the feasible range. From Table 4, it can be noted that the solutions with a higher actuation torque have thick magnets (high values of magnet thickness $\mathrm{x}_{1}$ ), small intercoil distance (low values of variable $x_{6}$ ) and high current values (variable $x_{7}$ ).

In turn, the dimensions of the coils (design variables $x_{4}$ and $x_{5}$, respectively) have values in the middle of the feasible range.

From Table 4, it can be also noted that the solutions with lowest system volume are characterized by small magnets and thin coils located close to the magnet (low values of variables $\mathrm{x}_{1}, \mathrm{x}_{2}, \mathrm{x}_{3}, \mathrm{x}_{4}$ ). In turn, the coils are larger and quite distant from each other; in fact, variables $x_{5}$ and $x_{6}$ do not affect the system volume calculation. The current in the coils is the maximum possible, given the current density constraint.

In general, for all the Pareto-optimal solutions identified, it can be noted that short magnets (low values for magnet length $\mathrm{x}_{2}$ ) are preferred and the distance between the coils and the magnet (design variable $\mathrm{x}_{3}$ ) is kept as small as possible.

Author Contributions: P.D.B. conceived the paper, assessed the results, wrote the Introduction and Section 2.3, and supervised the manuscript. P.D.B. and M.E.M. wrote the Discussion section. M.E.M. implemented the 3D model, ran the optimization and wrote the Results and the Material and Methods sections, except the description of the algorithms. E.S. implemented the optimization algorithm and wrote the relevant section in Materials and Methods. All authors have read and agreed to the published version of the manuscript.

Funding: This research received no external funding.

Conflicts of Interest: The authors declare no conflict of interest.

\section{References}

1. Jones, T.B.; Nenadic, N.G. Electromechanics and MEMS; Cambridge University Press: Cambridge, UK; New York, NY, USA, 2013; ISBN 978-0-521-76483-4.

2. Nathanson, H.C.; Newell, W.E.; Wickstrom, R.A.; Davis, J.R. The resonant gate transistor. IEEE Trans. Electron Devices 1967, 14, 117-133. [CrossRef]

3. Pelesko, J.A.; Bernstein, D.H. Modeling MEMS and NEMS; Chapman \& Hall/CRC: Boca Raton, FL, USA, 2003; ISBN 978-1-58488-306-7. 
4. Di Barba, P.; Mognaschi, M.E.; Venini, P.; Wiak, S. Biogeography-inspired multiobjective optimization for helping MEMS synthesis. Arch. Electr. Eng. 2017, 66. [CrossRef]

5. Di Barba, P.; Liu, B.; Mognaschi, M.E.; Venini, P.; Wiak, S. Multiphysics field analysis and evolutionary optimization: Design of an electro-thermo-elastic microactuator. Int. J. Appl. Electromagn. Mech. 2017, 54, 433-448. [CrossRef]

6. Zega, V.; Frangi, A.; Guercilena, A.; Gattere, G. Analysis of Frequency Stability and Thermoelastic Effects for Slotted Tuning Fork MEMS Resonators. Sensors 2018, 18, 2157. [CrossRef] [PubMed]

7. Zozulya, V.V.; Saez, A. A high-order theory of a thermoelastic beams and its application to the MEMS/NEMS analysis and simulations. Arch. Appl. Mech. 2016, 86, 1255-1272. [CrossRef]

8. Zhang, Y.; Wang, T.; Luo, A.; Hu, Y.; Li, X.; Wang, F. Micro electrostatic energy harvester with both broad bandwidth and high normalized power density. Appl. Energy 2018, 212, 362-371. [CrossRef]

9. Velosa-Moncada, L.; Aguilera-Cortés, L.; González-Palacios, M.; Raskin, J.-P.; Herrera-May, A. Design of a Novel MEMS Microgripper with Rotatory Electrostatic Comb-Drive Actuators for Biomedical Applications. Sensors 2018, 18, 1664. [CrossRef] [PubMed]

10. Di Barba, P.; Gotszalk, T.; Majstrzyk, W.; Mognaschi, M.; Orłowska, K.; Wiak, S.; Sierakowski, A. Optimal Design of Electromagnetically Actuated MEMS Cantilevers. Sensors 2018, 18, 2533. [CrossRef] [PubMed]

11. Di Barba, P.; Wiak, S. MEMS: Field Models and Optimal Design; Lecture Notes in Electrical Engineering; Springer International Publishing: Cham, Switzerland, 2020; Volume 573, ISBN 978-3-030-21495-1.

12. de Oliveira Hansen, R.; Mátéfi-Tempfli, M.; Safonovs, R.; Adam, J.; Chemnitz, S.; Reimer, T.; Wagner, B.; Benecke, W.; Mátéfi-Tempfli, S. Magnetic films for electromagnetic actuation in MEMS switches. Microsyst. Technol. 2018, 24, 1987-1994. [CrossRef]

13. Karami Mohammadi, A.; Ali, N.A. Effect of High Electrostatic Actuation on Thermoelastic Damping in Thin Rectangular Microplate Resonators. J. Theor. Appl. Mech. 2015, 53, 317. [CrossRef]

14. Majstrzyk, W.; Mognaschi, M.E.; Orłowska, K.; Di Barba, P.; Sierakowski, A.; Dobrowolski, R.; Grabiec, P.; Gotszalk, T. Electromagnetic cantilever reference for the calibration of optical nanodisplacement systems. Sens. Actuators A Phys. 2018, 282, 149-156. [CrossRef]

15. Cauchi, M.; Grech, I.; Mallia, B.; Mollicone, P.; Sammut, N. Analytical, Numerical and Experimental Study of a Horizontal Electrothermal MEMS Microgripper for the Deformability Characterisation of Human Red Blood Cells. Micromachines 2018, 9, 108. [CrossRef] [PubMed]

16. Zhu, J.; Liu, X.; Shi, Q.; He, T.; Sun, Z.; Guo, X.; Liu, W.; Sulaiman, O.B.; Dong, B.; Lee, C. Development Trends and Perspectives of Future Sensors and MEMS/NEMS. Micromachines 2019, 11, 7. [CrossRef] [PubMed]

17. Ouakad, H.M. Electrostatic fringing-fields effects on the structural behavior of MEMS shallow arches. Microsyst. Technol. 2018, 24, 1391-1399. [CrossRef]

18. Di Barba, P.; Fattorusso, L.; Versaci, M. Electrostatic field in terms of geometric curvature in membrane MEMS devices. Commun. Appl. Ind. Math. 2017, 8, 165-184. [CrossRef]

19. Rahaman, A.; Ishfaque, A.; Jung, H.; Kim, B. Bio-Inspired Rectangular Shaped Piezoelectric MEMS Directional Microphone. IEEE Sens. J. 2019, 19, 88-96. [CrossRef]

20. Versaci, M.; Angiulli, G.; Fattorusso, L.; Jannelli, A. On the uniqueness of the solution for a semi-linear elliptic boundary value problem of the membrane MEMS device for reconstructing the membrane profile in absence of ghost solutions. Int. J. Non-Linear Mech. 2019, 109, 24-31. [CrossRef]

21. Angiulli, G.; Jannelli, A.; Morabito, F.C.; Versaci, M. Reconstructing the membrane detection of a 1D electrostatic-driven MEMS device by the shooting method: Convergence analysis and ghost solutions identification. Comp. Appl. Math. 2018, 37, 4484-4498. [CrossRef]

22. Javaheri, H.; Ghanati, P.; Azizi, S. A Case Study on the Numerical Solution and Reduced Order Model of MEMS. Sens. Imaging 2018, 19, 3. [CrossRef]

23. Vinyas, M.; Kattimani, S.C. Investigation of the effect of $\mathrm{BaTiO}_{3} / \mathrm{CoFe}_{2} \mathrm{O}_{4}$ particle arrangement on the static response of magneto-electro-thermo-elastic plates. Compos. Struct. 2018, 185, 51-64. [CrossRef]

24. Imai, S.; Tsukioka, T. A magnetic MEMS actuator using a permanent magnet and magnetic fluid enclosed in a cavity sandwiched by polymer diaphragms. Precis. Eng. 2014, 38, 548-554. [CrossRef]

25. Feng, J.; Liu, C.; Zhang, W.; Hao, S. Static and Dynamic Mechanical Behaviors of Electrostatic MEMS Resonator with Surface Processing Error. Micromachines 2018, 9, 34. [CrossRef] [PubMed] 
26. Mashinchi Joubari, M.; Asghari, R. Analytical Solution For Nnonlinear Vibration Of Micro-electromechanical System (mems) By Frequency-amplitude Formulation Method. J. Math. Comput. Sci. 2012, 4, 371-379. [CrossRef]

27. Di Barba, P.D.; Fattorusso, L.; Versaci, M. A 2D Non-Linear Second-Order Differential Model for Electrostatic Circular Membrane MEMS Devices: A Result of Existence and Uniqueness. Mathematics 2019, 7, 1193. [CrossRef]

28. Versaci, M.; Morabito, F.C. Membrane Micro Electro-Mechanical Systems for Industrial Applications. In Handbook of Research on Advanced Mechatronic Systems and Intelligent Robotics; Habib, M.K., Ed.; IGI Global: Hershey, PA, USA, 2020; pp. 139-175. ISBN 978-1-79980-137-5.

29. Fattorusso, L.; Versaci, M. A New One-Dimensional Electrostatic Model for Membrane MEMS Devices. In Proceedings of the Lecture Notes in Engineering and Computer Science, London, UK, 4-6 July 2018; p. 2235.

30. Fattorusso, L.; Versaci, M. A New Mathematical Model for a Membrane MEMS Device. In Transactions on Engineering Technologies; Ao, S.-I., Gelman, L., Kim, H.K., Eds.; Springer Singapore: Singapore, 2019; pp. 1-17. ISBN 978-981-329-530-8.

31. Daeichin, M.; Ozdogan, M.; Towfighian, S.; Miles, R. Dynamic response of a tunable MEMS accelerometer based on repulsive force. Sens. Actuators A Phys. 2019, 289, 34-43. [CrossRef]

32. Morabito, E.C.; Versaci, M. A fuzzy neural approach to localizing holes in conducting plates. IEEE Trans. Magn. 2001, 37, 3534-3537. [CrossRef]

33. Angiulli, G.; Versaci, M. A Neuro-Fuzzy Network for the Design of Circular and Triangular Equilateral Microstrip Antennas. Int. J. Infrared Millim. Waves 2002, 23, 1513-1520. [CrossRef]

34. Guckel, H. Progress in magnetic microactuators. Microsyst. Technol. 1998, 5, 59-61. [CrossRef]

35. Guckel, H.; Earles, T.; Klein, J.; Zook, D.; Ohnstein, T. Electromagnetic Linear Actuators With Inductive Position Sensing For Micro Relay, Micro Valve And Precision Positioning Applications. In Proceedings of the International Solid-State Sensors and Actuators Conference-TRANSDUCERS '95, Stockholm, Sweden, 25-29 June 1995; Volume 1, pp. 324-327.

36. Delinchant, B.; Rakotoarison, H.L.; Ardon, V.; Chadebec, O.; Cugat, O. Gradient based optimization of semi-numerical models with symbolic sensitivity: Application to a simple ferromagnetic MEMS switch device. Int. J. Appl. Electromagn. Mech. 2009, 30, 189-200. [CrossRef]

37. Di Barba, P.; Wiak, S. Evolutionary Computing and Optimal Design of MEMS. IEEE/ASME Trans. Mechatron. 2015, 20, 1660-1667. [CrossRef]

38. Di Barba, P.; Savini, A.; Wiak, S. Higher-order multiobjective design of MEMS. Int. J. Appl. Electromagn. Mech. 2017, 53, S239-S247. [CrossRef]

39. MagNet. Available online: https://www.mentor.com/products/mechanical/magnet/magnet/ (accessed on 20 July 2020).

40. Di Barba, P.; Mognaschi, M.E.; Rezaei, N.; Lowther, D.A.; Rahman, T. Many-objective shape optimisation of IPM motors for electric vehicle traction. Int. J. Appl. Electromagn. Mech. 2019, 60, S149-S162. [CrossRef]

41. Di Barba, P. Multiobjective Shape Design in Electricity and Magnetism; Lecture Notes in Electrical Engineering; Springer: Doredrecht, The Netherlands; New York, NY, USA, 2010; ISBN 978-90-481-3079-5.

42. Deb, K.Multi-Objective Optimization Using Evolutionary Algorithms, 1st ed.; Wiley-Interscience Series in Systems and Optimization; John Wiley \& Sons: Chichester, UK; New York, NY, USA, 2001; ISBN 0-471-87339-X.

43. Deb, K.; Pratap, A.; Agarwal, S.; Meyarivan, T. A fast and elitist multiobjective genetic algorithm: NSGA-II. IEEE Trans. Evol. Comput. 2002, 6, 182-197. [CrossRef]

44. Lahanas, M.; Schreibmann, E.; Milickovic, N.; Baltas, D. Evolutionary Multi-Criterion Optimization. In Lecture Notes in Computer Science; Springer: Berlin/Heidelberg, Germany, 2003; Volume 632, p. 70. ISBN 978-3-540-01869-8.

45. Nourbakhsh, A.; Safikhani, H.; Derakhshan, S. The comparison of multi-objective particle swarm optimization and NSGA II algorithm: Applications in centrifugal pumps. Eng. Optim. 2011, 43, 1095-1113. [CrossRef]

46. Li, H.; Zhang, Q. Multiobjective Optimization Problems with Complicated Pareto Sets, MOEA/D and NSGA-II. IEEE Trans. Evol. Comput. 2009, 13, 284-302. [CrossRef]

47. Sieni, E.; Di Barba, P.; Forzan, M. Migration NSGA: Method to improve a non-elitist searching of Pareto front, with application in magnetics. Inverse Probl. Sci. Eng. 2016, 24, 543-566. [CrossRef] 
48. Bertani, R.; Forzan, M.; Sgarbossa, P.; Sieni, E.; Di Barba, P.; Spizzo, F.; Del Bianco, L. Multi-objective Design of a Magnetic Fluid Hyperthermia Device. In Proceedings of the Industrial Electronics Society, IECON 2015-41th Annual Conference of the IEEE, Yokohama, Japan, 9-12 November 2015.

49. Di Barba, P.; Dughiero, F.; Mognaschi, M.E.; Sieni, E. Multi-objective optimization of an electrode pair for electrochemotherapy: M-NSGA and $\mu$-BIMO comparison. Int. J. Appl. Electromagn. Mech. 2019, 60, S163-S172. [CrossRef]

50. Di Barba, P.; Dughiero, F.; Forzan, M.; Sieni, E. Self-adaptive NGSA algorithm and optimal design of inductors for magneto-fluid hyperthermia. COMPEL Int. J. Comput. Math. Electr. Electron. Eng. 2017, 36, 535-545. [CrossRef]

51. Sieni, E.; Di Barba, P.; Dughiero, F.; Forzan, M. Self-adaptive migration NSGA and optimal design of inductors for magneto-fluid hyperthermia. Eng. Comput. 2018, 35, 1727-1746. [CrossRef]

52. Di Barba, P.; Dughiero, F.; Forzan, M.; Sieni, E. SELF-adaptive Migration-NSGA algorithm: An application in uncertainty-tolerant magnetic field synthesis for MFH inductor design. Int. J. Appl. Electromagn. Mech. 2018, 56, 17-32. [CrossRef]

53. Deb, K.; Jain, H. An Evolutionary Many-Objective Optimization Algorithm Using Reference-Point-Based Nondominated Sorting Approach, Part I: Solving Problems with Box Constraints. IEEE Trans. Evol. Comput. 2014, 18, 577-601. [CrossRef]

54. Das, I.; Dennis, J.E. Normal-Boundary Intersection: A New Method for Generating the Pareto Surface in Nonlinear Multicriteria Optimization Problems. SIAM J. Optim. 1998, 8, 631-657. [CrossRef]

(C) 2020 by the authors. Licensee MDPI, Basel, Switzerland. This article is an open access article distributed under the terms and conditions of the Creative Commons Attribution (CC BY) license (http://creativecommons.org/licenses/by/4.0/). 